\title{
Contribution to the Knowledge of the Genus Proceratium Roger (Hymenoptera: Formicidae: Proceratiinae) in the New World
}

\author{
IO FERNANDES ${ }^{1}$, JHC DELABIE ${ }^{2,3}$, F FERNÁNDEZ $^{4}$
}

1 - Instituto Nacional de Pesquisas da Amazônia - INPA, Coordenação em Biodiversidade, Coleção de Invertebrados, Manaus - AM. Brazil

2 - Laboratório de Mirmecologia, Centro de Pesquisas do Cacau - CEPEC/CEPLAC, Itabuna-BA, Brazil

3 - Departamento de Ciências Agrárias e Ambientais, Universidade Estadual Santa Cruz - UESC, Ilhéus-BA, Brazil

4 - Instituto de Ciencias Naturales, Universidad Nacional de Colombia, Bogotá D.C. Colombia

\section{Article History}

\section{Edited by}

John Lattke, UFPR, Brazil

Received 23 April 2019

Initial acceptance 13 May 2019

Final acceptance 26 September 2019

Publication date 30 December 2019

\section{Keywords}

Type material, hypogeic ant, new records, new species, $P$. micrommatum species key.

\section{Corresponding author}

Itanna Oliveira Fernandes

Instituto Nacional de Pesquisas da Amazônia

Coordenação em Biodiversidade

Coleção de Invertebrados

Av. André Araújo, 2936, Petrópolis

CEP: 69067-375 - Manaus-AM. Brasil.

E-Mail: itanna.fernandes@gmail.com

\begin{abstract}
The genus Proceratium Roger comprises rare ants that are irregularly distributed in tropical and temperate regions of the world. Despite this global distribution, these ants are rarely collected, likely due to their cryptobiotic lifestyle. In the New World, the genus comprises 22 known species distributed from Southern Canada to the South of Brazil, and in some Caribbean islands. The taxonomy of the genus Proceratium is here updated for South America. We describe $P$. amazonicum sp. nov, from Rondônia state and provide distribution data for $P$. brasiliense, $P$. convexipes, and $P$. silaceum. We also present, for the first time, high-resolution images of the $P$. colombicum type and $P$. ecuadoriense, and provide a new record of $P$. micrommatum from Peru, and comment about its morphological variation and distribution. A key for the workers of the $P$. micrommatum clade is also provided. The species we describe belongs to $P$. micrommatum clade and represents the second species recorded from Brazil after 60 years, since only $P$. brasiliense was known previously in the country.
\end{abstract}

urn:Isid:zoobank.org:pub:61AB6382-BCDE-4D1D-B57A-9D5AD65E64DE

\section{Introduction}

The genus Proceratium Roger, 1863 consists of rare ants that are distributed irregularly in the tropical and temperate areas of the world (Baroni Urbani \& de Andrade, 2003). The genus consists of 85 valid extant and six fossil species (Bolton, 2019). The taxonomy of the genus was relatively well resolved on a global scale by Baroni Urbani and de Andrade (2003). Taxonomic studies are also available for the Afrotropical Region (Hita Garcia et al., 2014), Fiji (Hita Garcia et al., 2015), Samoa and Pacific Islands (Liu et al., 2015), and China (Staab et al., 2018). Despite this global distribution, these ants are only rarely collected, likely due to their cryptobiotic lifestyle in leaf litter or soil (Baroni Urbani \& de Andrade, 2003).
The natural history of this genus is known from only few fragmentary reports (Brown 1974; 1979, Hita Garcia et al., 2014). Most Proceratium nest in rotten wood, in the ground, under stones, or in trees, and colonies appear to be rather small, usually with 10-50 workers (Brown, 1958; Brown, 1974; Baroni Urbani \& de Andrade, 2003), although Fisher (2005) recorded more than 350 workers in a nest of Proceratium avium Brown, 1974. African Proceratium species were collected at lower elevations, in dry sand forest of the Gorongosa National Park in Mozambique. The species are not restricted to low elevation, individuals from $P$. nilo Hita et al. (2014) were collected at $1000 \mathrm{~m}$ in the Tanga region in Tanzania, as well as P. sali Hita Garcia et al. (2014) collected at an elevation between approximately 1150 to $1480 \mathrm{~m}$. The specialized predation of Proceratium species on arthropod 
eggs, especially spider eggs, was first suggested by Brown (1958), who succeeded in keeping a colony of $P$. silaceum Roger in the laboratory by feeding them almost exclusively with spider eggs. However, Masuko (2019) recently reported data on 107 P. itoi (Forel, 1918) colonies from the Manazuru forest, in Japan, 90 of which were complete or near complete colonies (workers, queens and larvae). Although a total of more than 1,700 arthropod eggs were collected from the ant nests, none of them were from spiders (Masuko, 2019).

Due to the rarity of specimens in collections, there is very little information about intra- and interspecific variation (Hita Garcia et al., 2014). Surface sculpture is a commonly used character for species level identification (Hita Garcia et al., 2014), although it appears to be relatively variable. However, the lack or presence of abundant, long, standing pilosity on top of a very dense mat of subdecumbent to decumbent hairs seems to be species-specific (Hita Garcia et al., 2014).

In the New World, the genus comprises 22 known species distributed from southern Canada to the south of Brazil and in some Caribbean islands. To date, the most recent study in the Neotropical region is that of Sosa-Calvo and Longino (2008) and Escárraga et al. (2019) with keys adapted from Baroni Urbani and de Andrade (2003). Baroni Urbani and de Andrade (2003) also performed a species-level cladistic analysis in an attempt to infer the most probable relationships between the fossil and the extant Proceratium species. These analysis revealed eight species clades, within them, the $P$. micrommatum clade, with 15 Neotropical species.

In Brazil, the only species reported until now is $P$. brasiliense (Baroni Urbani \& de Andrade, 2003; Feitosa, 2015), recorded in the states of Bahia, Minas Gerais, Rio de Janeiro, São Paulo, and Santa Catarina (antmaps.org: Janicki et al., 2016). Here we describe a new Proceratium species for Brazil, give taxonomic notes for $P$. ecuadoriense and $P$. colombicum, with their respective type specimens, as well as a new locality record of P. micrommatum (Roger, 1863), as well as an updated key to the workers of the $P$. micrommatum clade.

\section{Material and methods}

\section{Abbreviations of depositories}

CEPEC: Centro de Pesquisas do Cacau, Ilhéus, Bahia, Brazil. IAvH: Instituto de Investigación de Recursos Biológicos Alexander von Humboldt, Villa de Leiva, Colombia.

INPA: Instituto Nacional de Pesquisas da Amazônia, Manaus, Amazonas, Brazil.

MCZ: Museum of Comparative Zoology, Cambridge, Massachusetts, U.S.A.

We follow the morphological nomenclature of Bolton (1994) and Baroni Urbani and de Andrade (2003). In order to describe pubescence and pilosity, we follow Wilson (1955) and use the terms "erect", "suberect", "subdecumbent", "decumbent" and "appressed". The terminology for the description of surface sculpturing is based on Harris (1979). Specimens were identified and measured using a Leica M250A stereomicroscope, with magnifications of 20x, 40x and 60x, under a white light. Digital images were made using the same equipment. All measurements are given in millimeters and the abbreviations used are:

HW: Head width. In full-face view, the maximum width of head.

HL: Head length. In full-face view, from the anterior edge of the clypeus to the medial posterior margin of the head.

EL: Eye length. In lateral view, maximum length of eye measured in oblique.

SL: Scape length. In frontal view, measured from apex of first antennal segment to base, excluding the basal condyle.

WL: Weber's length. In lateral view, the diagonal length of mesosoma in profile, from the midpoint of the anterior pronotal declivity to posterior margin of metapleuron.

PW: Pronotal width. In dorsal view, the maximum width of pronotum, measured from side to side.

PtH: Petiole height. In lateral view, the distance from lower edge of petiolar sternite to apex of petiolar tergite (node), taken as a vertical measurement perpendicular to the longitudinal axis of the petiole.

PtL: Petiole length. In lateral view, the maximum distance between anterior and posterior extremes of petiolar node, excluding anterior and posterior condyles.

PtW: Petiole width. In dorsal view, maximum width of petiole measured.

GL: Gaster length. In lateral view, the maximum length of gaster.

LT3: Abdominal tergum III length. In lateral view, maximum length of abdominal tergum III.

LS4: Abdominal sternum IV length. In lateral view, maximum length of abdominal sternum IV (following Ward, 1988).

LT4: Abdominal tergum IV length. In lateral view, maximum length of abdominal tergum IV (following Ward, 1988).

TL: Total length. The total outstretched length of the ant from the mandible apex to the gastral apex.

CI: Cephalic index. HW / HL x 100.

OI: Ocular index. EL / HW x 100.

SI: Scape index. SL / HL x 100.

DPeI: Dorsal petiole index. PtW / PtL x 100.

ASI: Abdominal segment index. LT4 / LT3 x 100.

IGR: Gastral reflexion index. LS4 / LT4

\section{Results}

Proceratium amazonicum Fernandes, Delabie \& Fernández, new species (Fig 1A-B; 2A-F)

urn:1sid:zoobank.org:act:07DAF714-AD3D-46BD-81FCBB311D55634B 


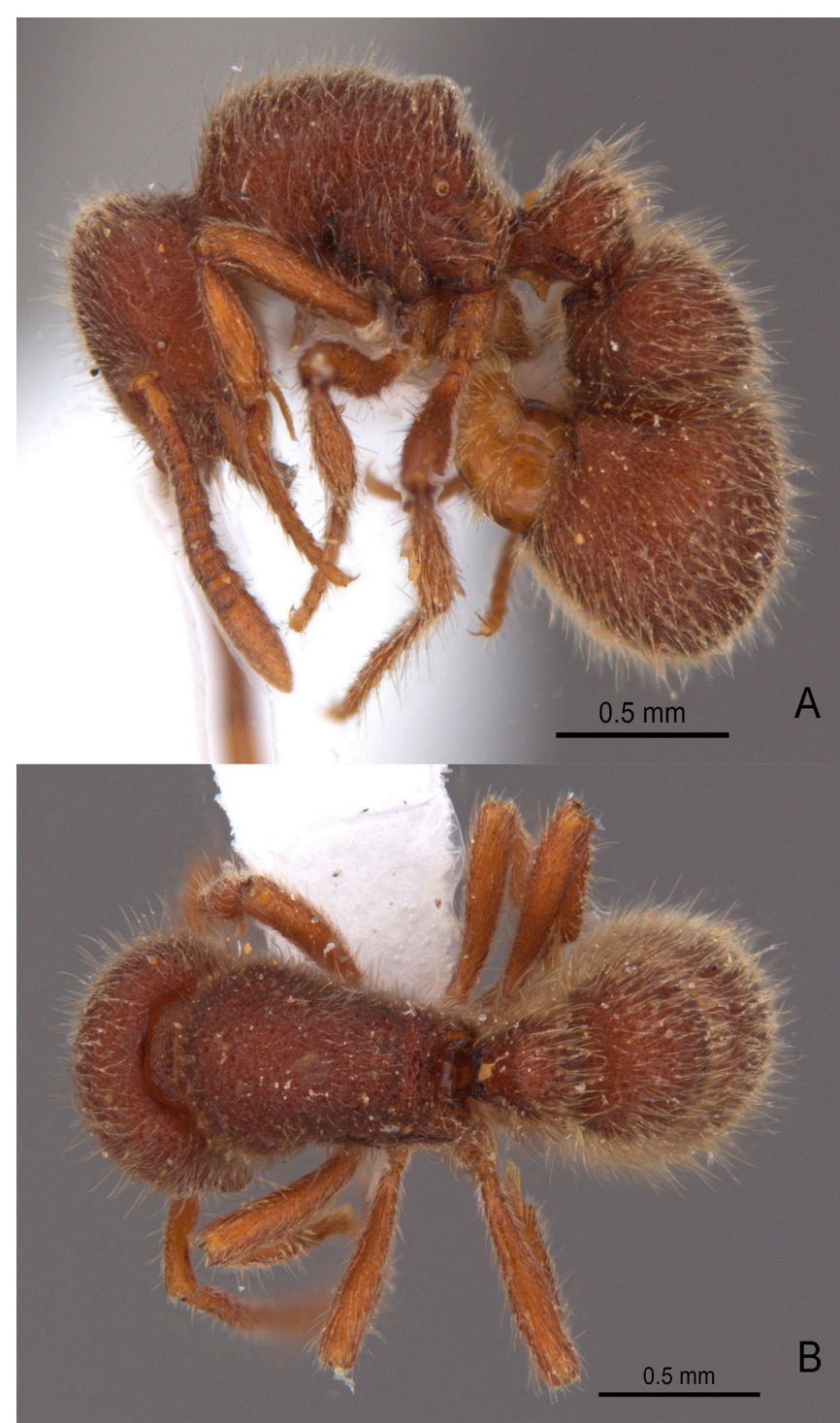

Fig 1A-B. Proceratium amazonicum sp. nov. Lateral view (A) and dorsal view (B).

Type material: Holotype worker. BRAZIL, Rondônia, Floresta Nacional do Jamari (Flona Jamari), 630.1'24"W $9^{\circ} 09^{\prime} 40^{\prime \prime}$ S, Serra da Onça, Novo Mundo, 10.i.2018, soil sample on the ground, D.C. Castro col., INPA (1 worker).

Etymology: "amazonicum" is a neologism indicating the provenance of this species from the Amazon (Rondônia state).

Diagnosis: Frontal triangle on head elevated; mandible with 4 denticles (including the apical tooth); propodeal tumulus narrow and high; long, erect or suberect hairs on petiole and dorsum of abdominal segment III; large species TL: > 3.00 $\mathrm{mm}$; body densely foveolate.

Holotype measurements: SL: 0.52, HW: 0.70, HL: 0.79, EL: 0.03, WL: 0.86, PW: 0.48, PtL: 0.28, PtH: 0.26, PtW: 0.28, LT3: 0.35, LT4: 0.60, LS4: 0.18, GL: 0.97, TL: 3.39, CI: 88, OI: 4, SI: 65, IGR: 0.30, ASI: 171, DPeI: 100.

Worker description. (Figs 1A-B; 2A-F).

Head longer than broad; sides slightly narrower anteriorly than posteriorly. Vertex in full face view convex.
Clypeus recognizable as small triangular or subtriangular tooth between antennal sockets. Frontal carinae close to each other, not covering antennal insertions. Lateral expansions of the frontal carinae relatively narrow, raised and diverging posteriorly. Frontal triangle elevated. Genal carinae strongly marked. Sulcus between genal carinae and gular area impressed. Eyes present, composed of 6-7 convex facets slightly below midline of head. Scapes thicker in distal half and far short of vertexal margin. First funicular joint 1/4 longer than broad. Mandible with 4 denticles including the apical tooth.

Mesosoma slightly elongate. Promesopleural and mesometapleural sutures weakly impressed. Propodeum with elevated tumosity (tumulus) on apex, before the declivity. Declivous face of propodeum flat, sides crenulate and concave close to propodeal lobes. Propodeal lobe semitransparent. Propodeal spiracle tumuliform. Petiole slightly longer than broad, with sides subparallel in anterior third and convex posteriorly in dorsal view. Anterior border of petiole straight. In lateral, view of the basal area of petiole slightly smaller than the apex. Ventral process of petiole triangular, semitransparent and sharply pointed. Abdominal segment III (G1 tergite) slightly shorter than 1/3 length of abdominal segment IV (G2 tergite), in lateral view. Abdominal segment III (G1 sternite) with ventral carina, close to anterior border. Abdominal segment IV (G2 sternite), ventrally with marked subround convex projection. Abdominal segment IV (sternite) slightly convex. Constriction between abdominal segments III and IV strongly impressed. Abdominal sternite III very short medially, carinate and protruding anteriorly on sides.

Mid tibiae without pectinate spur. Spurs of fore legs without basal spine. Fore basitarsi longer than mid and hind ones. Pretarsal claws simple. Arolia small.

Sculpture. Head, mesosoma, petiole and gaster densely foveolate. Legs foveolate.

Body covered by hairs of three main types: (1) short, dense, subdecumbent on whole body, very dense on dorsal face of propodeum tumulus, sparse and erect on funicular joints; (2) long, erect or suberect on petiole and on abdominal segment III (G1 sternite, lateral view); sparse on whole body, absent from tumulus of basal face of propodeum and on antennae. Appressed, short and sparse hairs present on head.

Colour ferrugineous-brown with slightly lighter antennae and legs.

Distribution. Brazil (Rondônia).

Observations. The single specimen of this new species was collected in soil at a depth of $10 \mathrm{~cm}$ in an area of $25 \times 25$ cm (TSBF trap, Anderson \& Ingram, 1993). A soil sample was placed in a Winkler extractor (Bestelmeyer et al., 2000) for 48 hours. The material was obtained in the federal reserve of Floresta Nacional do Jamari (FLONA do Jamari) located on the grounds of the municipalities of Cujubim, Porto Velho, Ariquemes and Itapuã do Oeste, in the state of Rondônia, Brazil.

Additional examined material. 


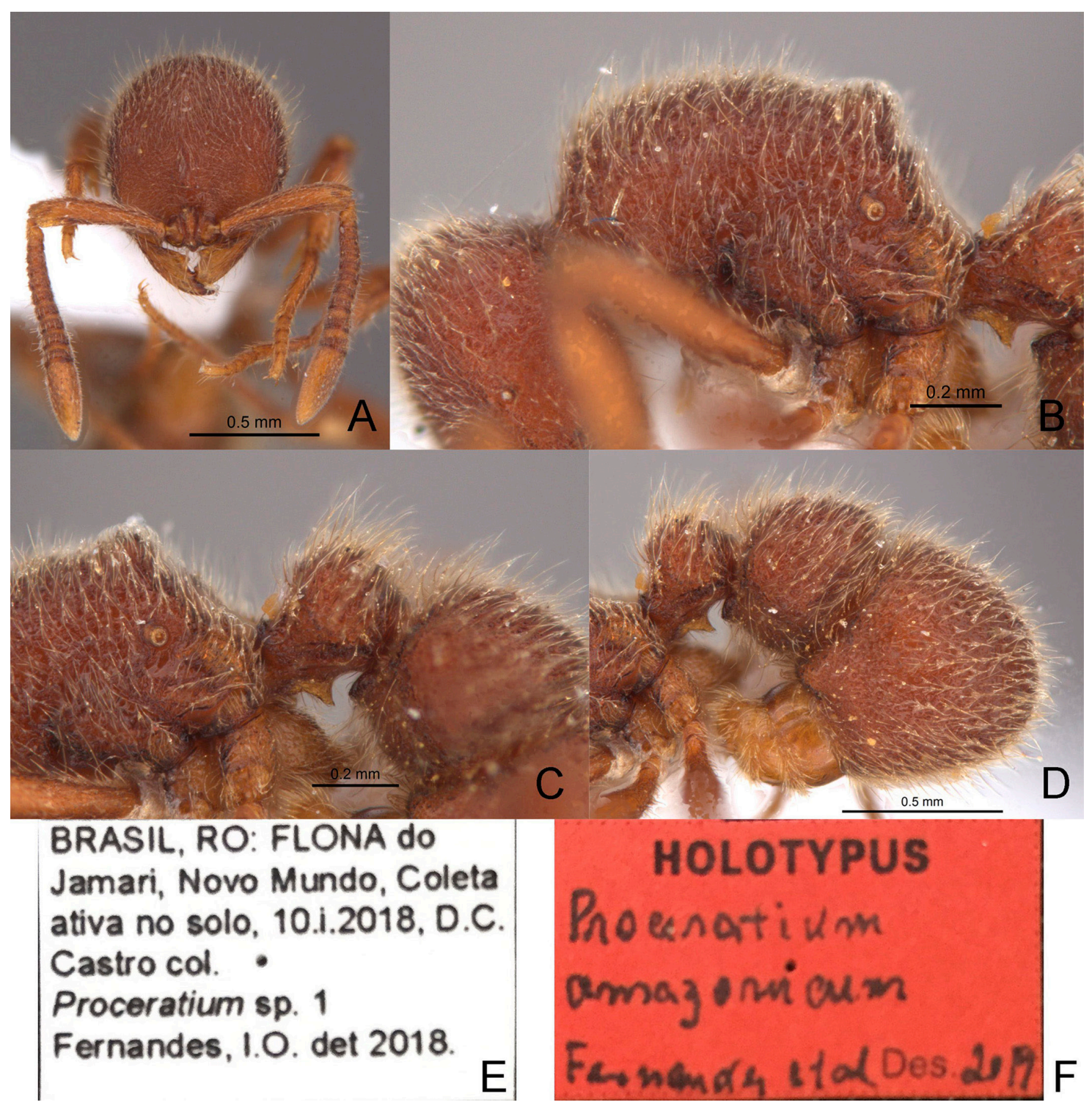

Fig 2A-F. Proceratium amazonicum sp. nov. Head in frontal view (A), mesosoma in lateral view (B), mesosoma and petiole in lateral view (C), petiole and gaster in lateral view (D), locality (E) and designation (F) label.

\section{Proceratium brasiliense Borgmeier, 1959.}

BRAZIL: Bahia: Ilhéus, CEPEC, \#4374, 1986, J. Delabie col. [id. M.L. de Andrade] (1 worker) (CPDC); Ilhéus, Praia do Norte, 02.vi.1994, 8:00 (mating flight), J.H.C. Delabie col. [id. M.L. de Andrade] (2 alate gynes) (CPDC); Ilhéus, Praia do Norte, 19.iii.1995, 7:00 (mating flight) (1 alate gyne) (CPDC); Ilhéus, Praia do Norte, 30.i.1996 (mating flight), I.C. do Nascimento col. (1 alate gyne) (CPDC); São Paulo: Cananeia, 23.x.2002 \#5395, L.P.M. Macedo col. (1 worker) (CPDC).

\section{Proceratium convexiceps Borgmeier, 1957.}

PANAMA: Colon. IBISCA, San Lorenzo Forest, FLC2B28a, 17.x.2003, no colector, labelled "Proceratium sp.2" (1 alate gyne) (CPDC).

Proceratium colombicum de Andrade, 2003 (Fig 3A-D)
Type material: Holotype worker from Colombia labelled: "Nariño, Orito, Territorio Kofan, $00^{\circ} 30^{\prime} \mathrm{N} 77^{\circ} 13^{\text {' }}$ W, 1000 m, 25.ix.1998, E. L. Gonzalez”, in IAvH [examined].

\section{Proceratium ecuadoriense de Andrade, 2003 (Fig 4A-D)}

Type material: Holotype worker from Ecuador labelled: "Ecuador: Prov. Pichincha, S. \& J. Peck, 1975, Tinalandia, $16 \mathrm{~km}$ SES. Domingo de los Colorados, Jun, MCZ Holotype 35014".

Proceratium micrommatum (Roger, 1863) (Fig 5A-D; 6A-D).

PANAMA: Colon, San Lorenzo Forest, $9^{0} 17^{\prime} \mathrm{N} 79^{\circ} 54^{\prime} \mathrm{W}$, M-G-Z-06 Berleze, R1, 18.x.2003, N. Winchester \& K. Jordan col. (1 worker) (CPDC); IBISCA, San Lorenzo Forest, FIT-R1-14/5, 27-28.x.2003, A. Tishechkin col., labelled "Proceratium sp.1" (3 alate gynes) (CPDC); IBISCA, San Lorenzo Forest, FIT-R2-11, 17-18.v.2004, A. Tishechkin col., 


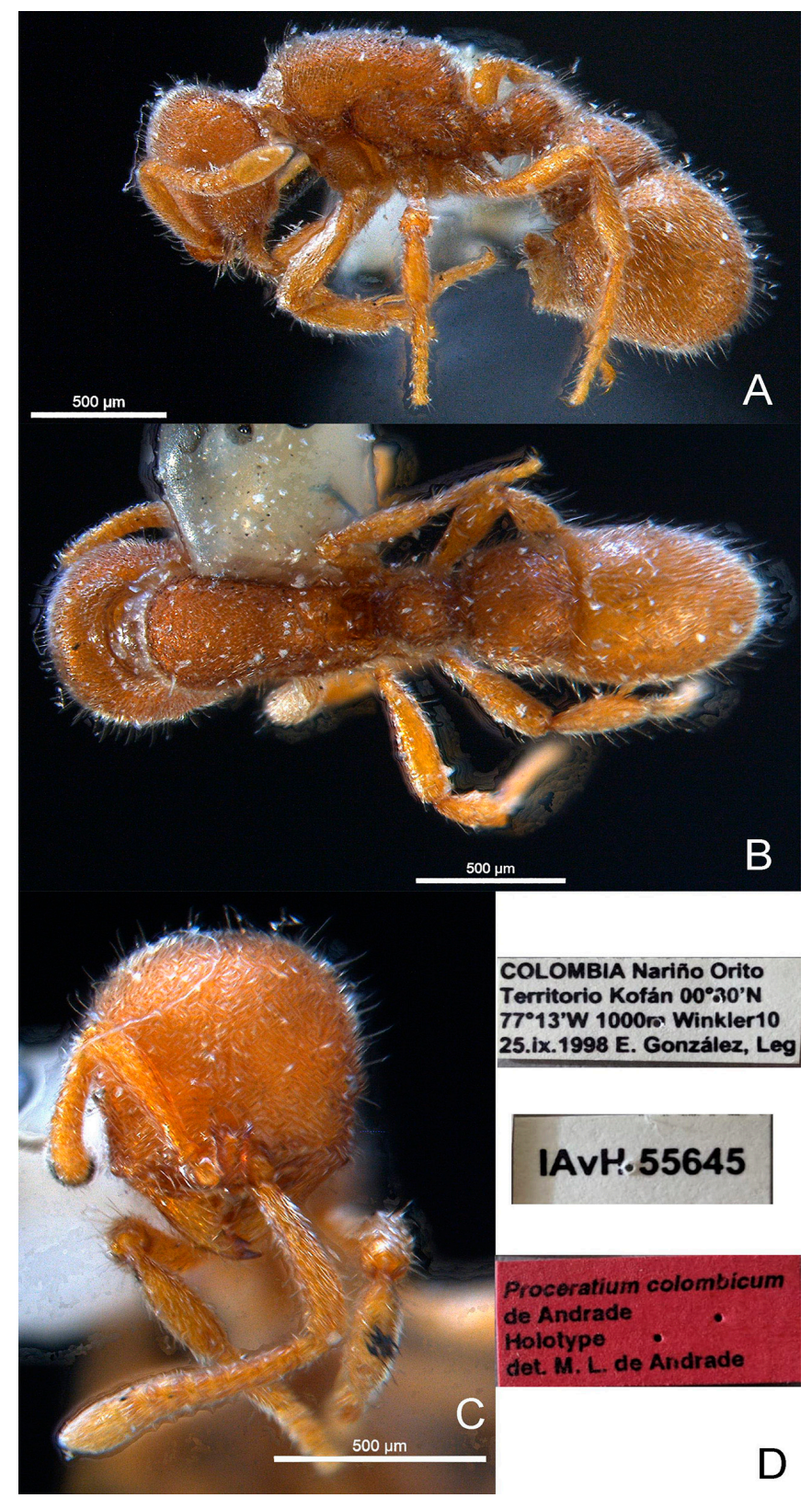

Fig 3A-D. Proceratium colombicum. Holotype. Lateral view (A), dorsal view (B), head in frontal view (C), label (D). Photos provided by María Camila Tocora and Gianpiero Fiorentino, IAvH 55645.

labelled "Proceratium sp.1" (5 alate gynes) (CPDC). PERU: Porto Maldonado, Madre de Dios, Estação Sachavacayoc, 12 ${ }^{\circ} 51^{\prime} 09,6$ 'S 69²2'00.3”W, 20.vii.2012, Neotropical Ant Course, Trilha do Condenado I, after bridge, extrator Winkler, I.O. Fernandes et al., col., (1 worker) (INPA); MD [Madre de Dios], Reserva Nacional Tambopata, Sachavacayoc, 1251'21's 69²1'43'W, 210m, 19-31.vii.2012, [R.M] Feitosa col., Neotropical Ant Course, UFV LABECOL n. 000044 (1 worker) (INPA).

P. micrommatum workers measurements $(\mathrm{n} .=2)$. SL: 0.39-0.43, HW: 0.58-0.60, HL: 0.60-0.64, EL: 0.03, WL: 0.70-0.73, PW: 0.38-0.39, PtL: 0.23-0.25, PtH: 0.25-0.26, PtW: 0.23-0.24, LT3: 0.25-.30, LT4: 0.60-0.61, LS4: 0.150.16, GL: 0.88-0.91, TL: 2, CI: 93-96, OI: 5, SI: 65-67, IGR: 0.25-0.26, ASI: 203-240, DPeI: 96-100.

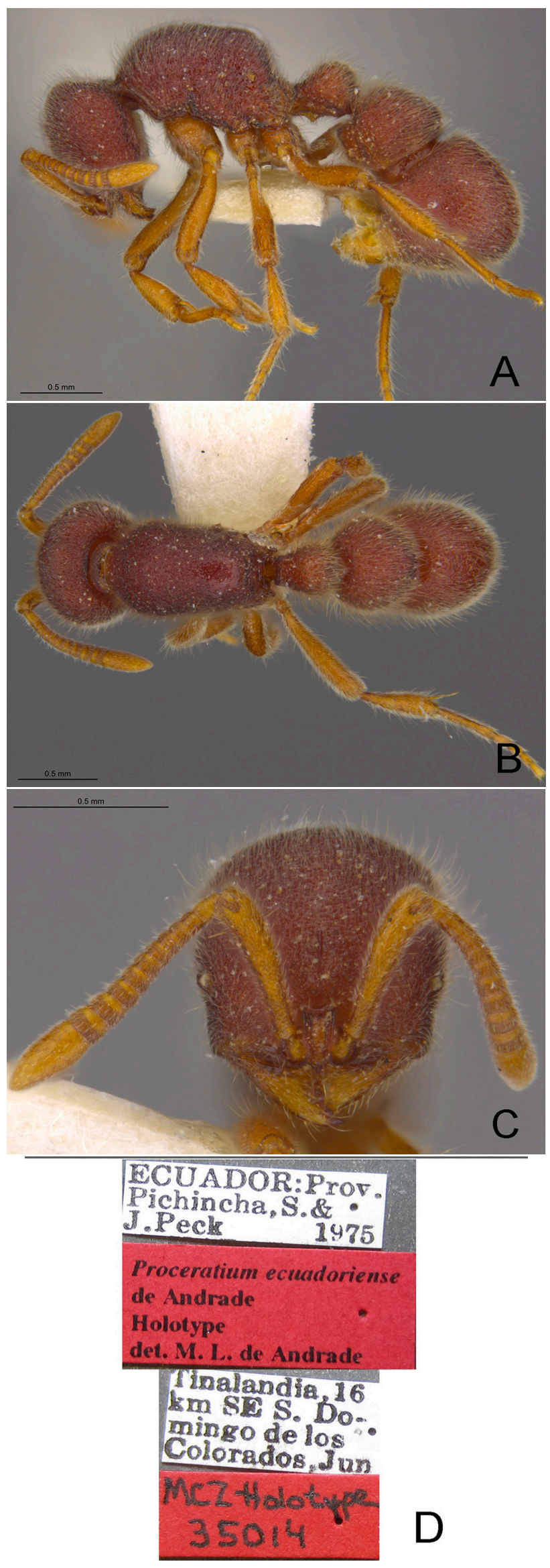

Fig 4A-D. Proceratium ecuadoriense. Holotype. Lateral view (A), dorsal view (B), head in frontal view (C), label (D). Photos provided by Stefan Cover, MCZ 35014. 


\section{Proceratium silaceum Roger, 1863.}

MEXICO: Veracruz, Est. Los Tuxtlas, 23.ix.1992. L. Quiroz col. (1 worker) (CPDC); USA: Florida, 5.5 miles N. Gainesville, 05.iii.1992, LR. Davis Jr. [id. M.L. de Andrade] (8 workers) (CPDC).

Key to workers of Proceratium species from $P$. micrommatum clade (modified from Baroni Urbani \& de Andrade, 2003). The fossil species $P$. dominicanum and $P$. poinari, as well as $P$. longiscapus known on the gyne only, are excluded from this key.

1. Spur of the mid tibia not pectinate 2

- Spur of the mid tibia pectinate

2. Dorsal part of propodeum with a tumulus covered only with short hairs ... 3

- Dorsal part of propodeum without a tumulus, covered with long and short hairs .... 7

3. Gaster completely sculptured 4

- Sculpture present only in the midle or less on the gaster ..... 6

4. Small species TL: $<2.90$ colombicum (Colombia: Nariño)

- Large species TL:> 3.20 5

5. Head, mesosoma and gaster reticulate-faveolate and granulate; tumulus on the propodeum broad and low

P. ecuadoriense (Ecuador)

- Head mesosoma and gaster densely faveolate; tumulus on the propodeum narrow and high P. amazonicum sp. nov. (Brazil: Rondônia)

6. Petiole $1 / 5$ longer than broad. Postpetiole shorter than $1 / 2$ of the gastral tergite I; postpetiole and gaster more convex .......P. catio (Venezuela, Colombia and Ecuador)

- Petiole at most 1/8 longer than broad. Postpetiole slightly longer than $1 / 2$ of the gastral tergite I; postpetiole and gaster less convex P. brasiliense (Colombia and Brazil)

7. Mid basitarsi with hairs shorter than $1 / 2$ of the basitarsal length P. taino (Dominican Republic)

- Mid basitarsi with at least one hair about 1/2 of the mid basitarsal length .. 8

8. Area between the basal and declivous faces of the propodeum with a transverse carina angulate or denticulate laterally .. P. mexicanum (Southern USA to Guatemala)

- Area between the basal and declivous faces of the propodeum with at most very superficial traces of transverse carina ....... 9

9. Mesosoma gently convex in profile. Postpetiole in dorsal view more convex and slightly angulate anterolaterally. Integumental sculpture impressed.... P. convexiceps (Mexico to Ecuador)

- Mesosoma more elongate in profile. Postpetiole in dorsal view more rectangular and angulate anterolaterally. Body sculpture more superficial
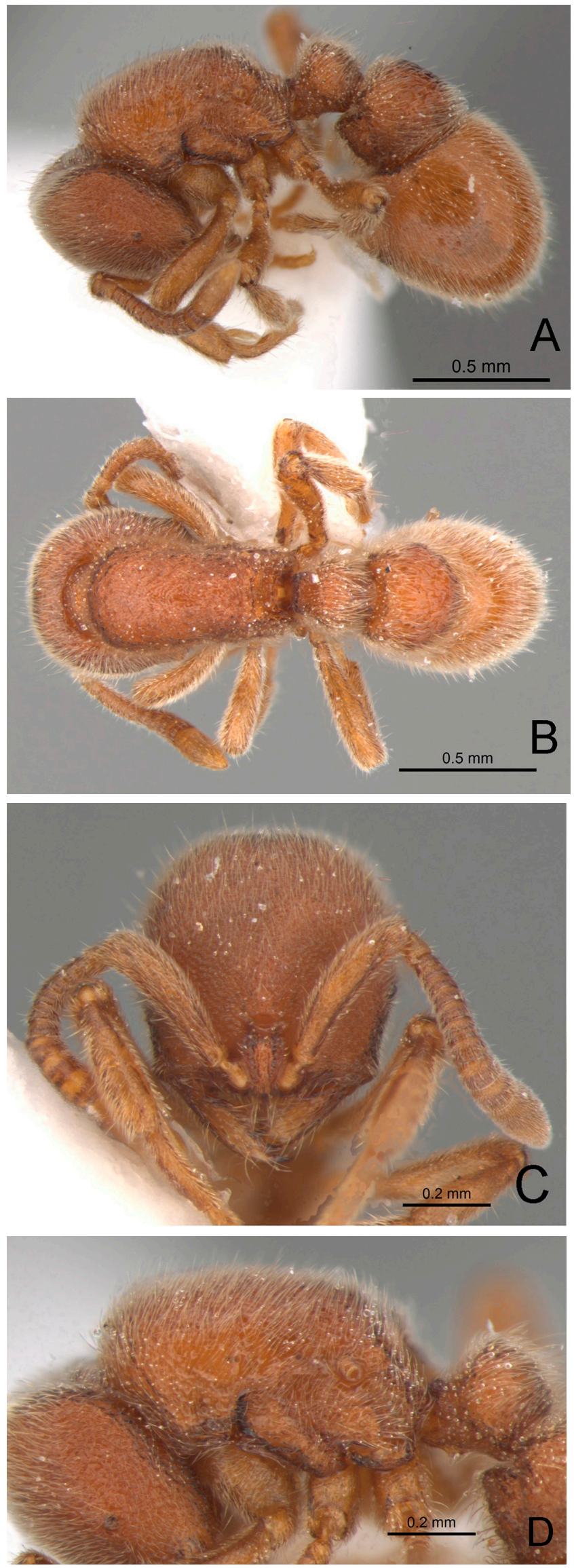

Fig 5A-D. Proceratium micrommatum. Lateral view (A), dorsal view (B), head in frontal view (C), mesosoma in lateral view (D). Specimen from Peru, Madre de Dios - Deposited in the INPA Collection. 


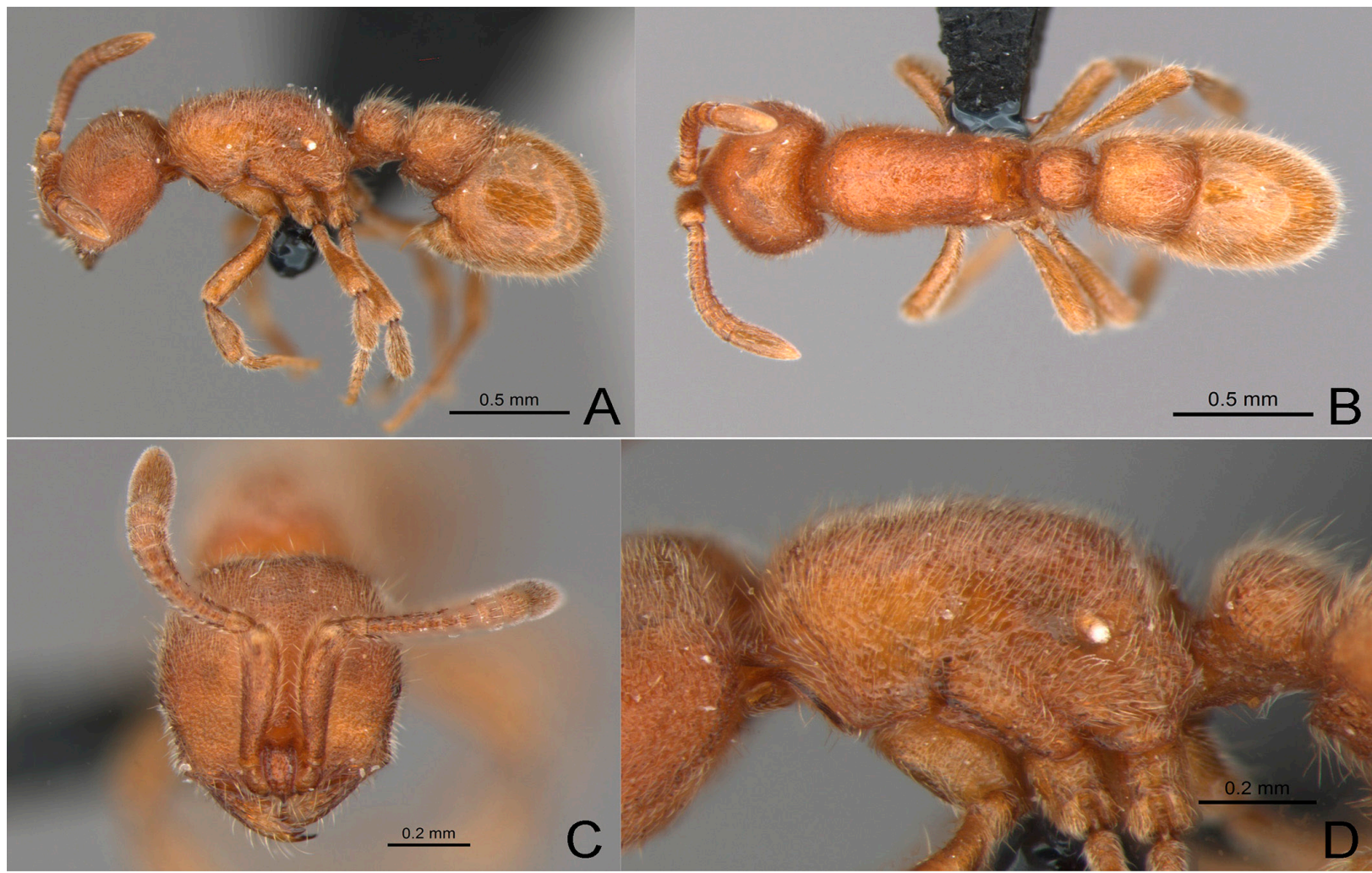

Fig 6A-D. Proceratium micrommatum. Lateral view (A), dorsal view (B), head in frontal view (C), mesosoma in lateral view (D). Specimen from Peru, Madre de Dios - Deposited in the INPA Collection (UFV LABECOL n. 000044).

10. TL: $\geq 3.80 \mathrm{~mm}$. WL: $\geq 1.05 \mathrm{~mm}$ (Costa Rica to Venezuela)

- TL: $<3.60 \mathrm{~mm}$. WL: $\leq 0.95 \mathrm{~mm}$ P. panamense (USA to Peru)

11. Clypeus surrounding the antennal sockets, subrectangular and protruding anteriorly. Propodeal dorsum with a median swelling ...... P. transitionis (Colombia)

- Clypeus not surrounding the antennal sockets, reduced medially and triangular. Propodeal dorsum without swelling P. lattkei (Venezuela)

\section{Discussion}

Proceratium amazonicum belongs to the $P$. micrommatum clade as defined by Baroni Urbani and de Andrade (2003). In the same phylogeny, a small group inside of the P. micrommatum clade is formed by the species $P$. brasiliense, $P$. catio, $P$. colombicum and $P$. ecuadoriense. All these species have the propodeal tumulus covered with short hairs on the dorsum, as does $P$. amazonicum sp. nov. Proceratium amazonicum sp. nov. can be easily distinguished from any other species in $P$. micrommatum clade, by the combination of total length over $3.00 \mathrm{~mm}$, with a tumulus on propodeum and has a completely sculptured gaster. Proceratium catio and P. brasiliense have sculpture limited to the middle of the gaster, while in $P$. amazonicum sp. nov. the gaster is completely sculptured. Proceratium colombicum is smaller $(\mathrm{TL}<2.90 \mathrm{~mm}$ in $P$. colombicum, $3.39 \mathrm{~mm}$ in $P$. amazonicum). Proceratium ecuadoriense also has a completely sculptured gaster, but the propodeal tumuli are broad and low in P. ecuadoriense, while in $P$. amazonicum they are narrow and high.

Proceratium convexiceps occurs in Costa Rica and Panama and a single worker of Mexico (El Ocotito) was attributed to this species with the possibility that it belongs to a different one (Baroni Urbani \& de Andrade, 2003). Proceratium colombicum is only known from its type locality, Nariño, in Colombia, and for the first time pictures with high resolution of the type species are presented here (Fig 3A-D). Proceratium colombicum appears as basal to $P$. brasiliense and $P$. catio (or sister to P. ecuadoriense) and differs from both, in the worker, by the following set of characters: head, mesosoma, petiole and postpetiole covered by dense granulation instead of granulate-rugulose foveolate, and first gastral tergite entirely densely granulate instead of densely granulate after the curvature only (Baroni Urbani \& de Andrade, 2003). Like in P. colombicum, P. ecuadoriense is only known from its type locality in Ecuador, and for the first time pictures with high resolution of type specimens are presented (Fig 4A-D). Proceratium ecuadoriense appears as the basal species of a small clade containing three additional species: P. brasiliense, P. catio and P. colombicum, but differs from these three taxa by the following two characteristics in the worker: broader and lower propodeal tumulus and deeper integumental sculpture.

Proceratium micrommatum (Fig 5A-D; 6A-D) is recorded 
for the first time in Peru. Aside from the original description, we compared the specimens with the type specimen photos available in antweb (FOCOL0932) (www.antweb.org). The specimen have a transverse carina on the declivous face of the propodeum and the anterior border of the petiole concave. The declivitous face of the propodeum presented some variations in the species (Fig 5A-D and 6A-D), which can be superficially marginate or marked, sometimes dentate (lateral margin of the declivity). Considering the P. micrommatum characteristics, the species can be easily confused with $P$. mexicanum, but the latter species has the propodeal carina strongly impressed. Baroni Urbani and de Andrade (2003) described $P$. mexicanum based on a misidentified P. micrommatum. The authors mentioned that if the interpretation of $P$. mexicanum was correct, a certain amount of geographic variability should characterize this species. The collection of additional material or a revisionary study might allow the separation of one or more species. In its current understanding, P. micrommatum has the widest distribution of all species of the genus in the New World and our record from Peru complements the distribution for South America given by Baroni Urbani and de Andrade (2003). The species was also recorded in Colombia (Sossa-Calvo \& Longino, 2008, Achury \& Suarez, 2017) and Ecuador (Salazar et al., 2015).

The Proceratium silaceum, a species belonging to the P. silaceum clade (Baroni Urbani \& de Andrade, 2003), is recorded here from Veracruz, Los Tuxtlas, Mexico. Another two records of $P$. silaceum from Veracruz, one with images, is available on antweb (PSW7415-1 and MMP01642 CASENT0733458) confirming the species distribution.

The description of Proceratium amazonicum sp. nov. raises the genus to 23 valid species in the New World, and represents the second species recorded from Brazil after 60 years, as previously only $P$. brasiliense was known for the country.

\section{Acknowledgments}

INPA for use of their facilities and the photographic equipment of the Invertebrate Collection, Maria Aurea Pinheiro de almeida Silveira for providing ants from Flona do Jamari (Brascan Recuperação Ambiental). I.O.F. acknowledges CAPES/PNPD for her research grant. Paulo V. Cruz for help with the figures. J.H.C.D. acknowledges CNPq for his research grant. Gianpiero Fiorentino helped with the English; John Longino for corrections and suggestions; the anonymous referees and the editor, John Lattke; María Camila Tocora and Gianpiero Fiorentino provided pictures of P. colombicum, Stefan Cover provided pictures of $P$. ecuadoriense.

\section{References}

Achury R. \& A.V. Suarez. (2017). Richness and composition of ground-dwelling ants in tropical rainforest and surrounding landscapes in the Colombian Inter-Andean valley. Neotropical Entomology, 47: 731-741. doi: 10.1007/s13744-017-0565-4
Anderson, J. M. \& Ingram, J. S. I. (Eds.) (1993). Tropical soil biology and fertility: A handbook of methods (2nd ed.). Wallingford CAB International, $237 \mathrm{p}$.

AntWeb v8.3.7 (2019). Available at: antweb.org

Baroni Urbani C. \& de Andrade, M.L. (2003). The ant genus Proceratium in the extant and fossil record (Hymenoptera: Formicidae). Museo Regionale di Scienze Naturali, Monografie, 36: 1-480. doi: 10.1002/mmnz.20040800210

Bestelmeyer, B.T., Agosti, D., Alonso, L.E., Brandão, C.R.F.R., Brown, W. Jr., Delabie, J.H.C. \& Silvestre, R. (2000). Field techniques for the study of ground-living ants: an overview, description, and evaluation. In: Agosti, D., Majer, J., Alonso, E. \& Schultz, T.R. (Eds.), Ants, Standard Methods for Measuring and Monitoring Biodiversity, (pp. 122-144). Washington, DC: Smithsonian Institution.

Bolton, B. (1994). Identification guide to the ant genera of the world. Cambridge: Harvard University Press, 222 p.

Bolton, B. (2019). An online catalog of the ants of the world. http://antcat.org [accessed 21 January, 2019]

Brown, W.L. (1958). Predation of arthropod eggs by the ant genera Proceratium and Discothyrea. Psyche, 64: 115. doi: $10.1155 / 1957 / 45849$

Brown, W.L. (1974). A remarkable new island isolate in the genus Proceratium (Hymenoptera: Formicidae). Psyche 81: 70-83. doi: 10.1155/1974/90949

Brown, W.L. (1979). A remarkable new species of Proceratium with dietary and other notes on the genus (Hymenoptera: Formicidae). Psyche, 86: 337-346. doi: 10.1155/1979/78461

Escárraga, M., Longino J.T \& Sosa-Calvo, J. (2019). Capítulo 23. Subfamilia Proceratiinae. Pp 681-691 in F. Fernández, R.J. Guerrero \& T. Delsinne (eds) Hormigas de Colombia, Universidad Nacional de Colombia, Bogotá D.C.

Feitosa, R.M. (2015). Estado da arte sobre a taxonomia e filogenia de Proceratiinae. In: Delabie, J.H.C., Feitosa, R.M., Serrão, J.E., Mariano, C.S.F. \& Majer, J.D. (Eds.), As formigas Poneromorfas do Brasil (pp. 81-83). Editus: Ilhéus, Bahia.

Forel, A. (1918). Études myrmécologiques en 1917. Bulletin de la Société Vaudoise des Sciences Naturelles, 51: 717-727.

Harris, R.A. (1979). A glossary of surface sculpturing. California Department of Food and Agriculture, Bureau of Entomology, 28: 1-31.

Hita Garcia, F., Hawkes, P. G. \& Alpert, G. D. (2014). Taxonomy of the ant genus Proceratium Roger (Hymenoptera, Formicidae) in the Afrotropical region with a revision of the $P$. arnoldi clade and description of four new species. ZooKeys, 447: 47-86. doi: 10.3897/zookeys.447.7766.

Hita Garcia, F., Sarnat, E.M. \& Economo, E.P. (2015). Revision of the ant genus Proceratium Roger (Hymenoptera, 
Proceratiinae Formicidae) in Fiji. Zookeys, 475: 97-112. doi. 10.3897/zookeys.475.8761

Janicki, J., Narula, N., Ziegler, M., Guénard, B. \& Economo, E.P. (2016). Visualizing and interacting with largevolume biodiversity data using client-server web-mapping applications: The design and implementation of antmaps.org. Ecological Informatics, 32: 185-193.

Liu, C., Fisher, B.L. \& Economo, E. P. (2015). A rare ant on Samoa: first record of the cryptic subfamily Proceratiinae (Hymenoptera, Formicidae) and description of a new Proceratium Roger species. Journal of Hymenoptera Research, 46: 35-44. doi: 10.3897/JHR.46.5849

Masuko, K. (2019). Predation on non-spider arthropod eggs and colony bionomics of the ant Proceratium itoi (Hymenoptera: Formicidae). Annals of the Entomological Society of America, 112: 372-378. doi: 10.1093/aesa/saz012

Roger, J. (1863). Die neu aufgeführten Gattungen und Arten meines Formiciden-Verzeichnisses nebst Ergänzung einiger früher gegebenen Beschreibungen. Berliner Entomologische Zeitschrift, 7: 131-214.

Salazar F., F. Reyes-Bueno, D. Sanmartin, \& D. A. Donoso.
2015. Mapping continental Ecuadorian ant species. Sociobiology, 62: 132-162.

Sosa-Calvo, J. \& Longino, J. (2008). Subfamilia Proceratiinae. In: Jiménez, E., Fernández, F.C., Arias, T.M. \& LozanoZambrano, F.H. (Eds.) Sistematica, Biogeografia y Conservación de las hormigas cazadoras de Colombia (pp. 219-327). Bogotá: Instituto de Inverstigación de Recursos Biolólogicos Alexander von Humboldt.

Staab, M., Hita Garcia, F., Liu, C., Xu, Z.H. \& Economo, E.H. (2018). Systematics of the ant genus Proceratium Roger (Hymenoptera: Formicidae: Proceratiinae) in China - with description of three new species based on micro-CT enhanced next-generation-morphology. Zookeys, 770: 137-192. doi: 10.3897/zookeys.770.24908.

Ward, P.S. (1988). Mesic elements in the Western Neartic ant fauna: taxonomic and biological notes on Amblyopone, Proceratium, and Smithistruma (Hymenoptera: Formicidae). Journal of the Kansas Entomology Society, 61: 102-124.

Wilson, E.O. (1955). A monographic revision of the ant genus Lasius. Bulletin of the Museum of Comparative Zoology, 113: 1-201.

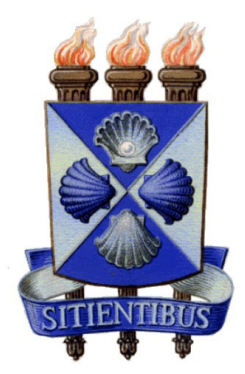

